\title{
Quest for COVID-19 cure: integrating traditional herbal medicines in the modern drug paradigm
}

\author{
Prativa Pandey ${ }^{1,2, ~ *}$, Angisha Basnet ${ }^{1,3, \#}$, and Aatish Mali ${ }^{1,4, \#}$ \\ ${ }^{1}$ Research Institute for Bioscience and Biotechnology (RIBB), Kathmandu, Nepal \\ ${ }^{2}$ Email: prativa@catalysttechnology.org, ORCID: 0000-0002-7905-5316 \\ ${ }^{3}$ Email: angishabasnet123.ab@gmail.com, ORCID: 0000-0002-9000-9062 \\ ${ }^{4}$ Email: mlkraatish@gmail.com , ORCID: 0000-0003-2565-7159 \\ \# These authors contributed equally to this paper and their names were written alphabetically.
}

Received: May 23, 2020; Accepted: June 14, 2020; Published: June 23, 2020

\begin{abstract}
The world is facing one of the biggest public health tragedies of our time, both in terms of socio-economic loss and death tolls due to the coronavirus COVID-19 pandemic. In a frantic race to find treatment for COVID-19, many interventions to discover drugs and vaccines are being expedited. Similarly, traditional herbal medicines are also being explored to find a cure for COVID-19. There are many traditional medicines that have exhibited promising antiviral and immuno-modulating properties against a plethora of infectious diseases like influenza, malaria, tuberculosis, and even COVID-19. Traditional medicine is an integral part of culture and practices in many countries with a vast and rich history of treating diseases. However, scientific research based drug development approaches and effective regulatory mechanisms, on par with modern medicine, should be implemented to ensure safety, efficacy and overall validity of traditional medicine. Incorporating evidence-based traditional medicines in modern drug development paradigms can help assure affordability, accessibility and acceptability of the treatment approach. Furthermore, it can create pharmacological synergism to tackle drug resistance. Altogether, every country should create a roadmap for modernization and revival of traditional knowledge to improve the health care system and be better prepared for health crises.
\end{abstract}

Keywords: complementary medicine; COVID-19; infectious disease; phytochemicals; traditional medicine

सारांशः कोविड-१९ महाव्याधिको कारण विश्वले सामाजिक, आर्थिक व्यय तथा जन मृत्युको दरको हिसाबले अहिले सम्मकै सबैभन्दा ठुलो जन स्वास्थ्य त्रासदी बेहोर्नु परिरहेको अवस्था छ। कोविड-१९ को उपचार पत्ता लगाउने दौडमा विभिन्न औषधि तथा खोपको खोज र आविष्कार द्रुत गतिमा कायम छ । त्यसै गरि परम्परागत जडिबुटी उपचार पद्धतीको पनि खोज भैरहेको छ। धेरै परम्परागत जडिबुटीहरुमा विभिन्न रोगहरु जस्तै इन्प्लिएन्जा, मलेरिया, क्षयरोग अनि कोविड-१९ सँग प्रतिरोध गर्न सक्ने क्षमता भएको प्रारम्भिक अनुस न्धानमा देखिएको छ। परम्परागत औषधि पद्धतिको उपयोगले विभिन्न सरुवा रोगको उपचार गरिएको वृहत ईतिहास हुनुको साथै परम्परागत औषधिको ज्ञान यी देशहरुका रिति र प्रथासँग पनि गाभिएका छन् । तसर्थ प्रमाणमा आधारित पारम्परिक जडिबुटी औषधि पद्धतिलाई आधुनिक औषधि विज्ञानमा समाबेश गर्दा यो उपचार पद्धति माथिको पहुच र ग्राह्यता पनि निश्चित गर्न सकिन्छ । परिणाम स्वरुप यी औषधिका तालमेलले गर्दा शुक्ष्म जिवाणुको औषधि प्रतिरोधात्मक क्षमता घट्न सक्छ। समग्रमा, हरेक देशले आफ्नो परम्परागत ज्ञानको आधुनिकीकरण, संरक्षण र पुर्नस्थापना गर्नको लािि दीर्घकालिन योजना निर्माण गर्नु पछ। यसो गर्नाले राष्ट्रय स्वास्थ्य प्रणाली सुदृढ हुनुका साथै भविष्यमा आउने स्वास्थ्य संकटको पनि सामना गर्न सकिन्छ।

\footnotetext{
* Corresponding author, E-mail: prativa@ catalysttechnology.org; Tel.: +977- 9818376038

(C) RECAST/TU
} 


\section{Introduction}

Infectious diseases are one of the leading causes of morbidity and mortality around the world. Few major infectious diseases that have claimed many human lives in the world, as epidemics or pandemics, are Ebola, SARS (severe acute respiratory syndrome), Malaria, AIDS (Acquired immuno-deficiency syndrome), Influenza, Tuberculosis and recently coronavirus COVID-19 (Ben et al., 2020). These diseases have inflicted a heavy socioeconomic burden on the people of many countries, despite enormous efforts to control them at both local and international levels. The gains against infectious diseases are particularly tricky and cannot be taken for granted because of their emerging and reemerging nature. Current coronavirus COVID-19 (SARS-CoV-2) pandemic has presented the world with one of the most difficult global public health crises of our time. Since its emergence in December 2019 in Wuhan city of China the virus has spread to every continent except Antarctica, with daily cases and deaths increasing exponentially accounting for a total of 5.2 million cases and 330 thousand deaths in 213 countries in a short span of just 5 months (Worldometer, 2020).

In the race to contain the rapid spread of this highly contagious novel coronavirus, various strategies are being implemented from social distancing, testing and tracing to research and development of drugs and vaccines. There are currently no FDA approved medicine and preventative vaccines to treat and cure COVID-19. Due to the urgency of the situation, other investigations include repurposing possibilities of already existing antiviral medications such as Favipiravir, Ribavirin, Chloroquine (Sharma and Maurya, 2020; Saxena, 2019) and exploration of different alternative and traditional medicines to prevent and treat COVID-19 (Ang et al., 2020; ul Qamar et al., 2020; Zhang et al., 2020). Particularly traditional herbal medicines are being extensively explored as potential COVID-19 management medication with fair share of applause and criticisms.

Traditional herbal medicine has been effectively used in treating and managing various diseases since hundreds and even thousands of years, as mentioned in several ancient manuscripts, textbooks and pharmacopeia as well. The efficacy and effectiveness of herbal medicine have been further confirmed scientifically through several studies-for example, the aqueous dandelion extract has shown to inhibit influenza A virus infection and reduce its polymerase activity, and marine seaweed extract has shown significant anti-dengue properties (Lin et al., 2014; Rastogi et al., 2020; Yang et al., 2020). With the advent of new technologies for modern drug development and due to ease of production, standardization, quality control, and quick effects, the traditional medicinal practices started getting shadowed over time and even became extinct in some cases. Even then, there is still huge dependence on natural products or traditional medicine as complementary medicine, especially in the developing world.

Over the past two decades, traditional and complementary medicine (T\&CM) has regained momentum into the "mainstream" medicine and is incorporated in the national policies of $96 \mathrm{WHO}$ member states (Figures 1 and 2) (World Health Organization [WHO] 2019). Most of these T\&CM approach were in line with traditional herbal medicinal practices such as indigenous traditional medicine, traditional Chinese medicine, Ayurvedic medicine, Unani medicine, Sowa-Rigpa (Amchi in Northern Nepal), Siddha Medicine, etc. Despite the current preoccupation with synthetic drugs, natural products derived from plants have been a major source of inspiration for modern drug discovery and development, especially as antibacterial and antitumor agents. In fact, $11 \%$ of the 252 drugs considered as basic and essential by the WHO were exclusively of flowering plant origin (Rates, 2001). In the US alone, of the top 150 prescription drugs, at least 118 drugs are based on natural sources and 74 percent come from plant sources (Roberson, 2008). Needless to say, the current changing landscape of traditional medicine has also invited skepticism due to boisterous claims (e.g., as cure of COVID-19) that lacks sufficient evidence. Traditional medicines do not refute scientific knowledge and in fact many traditional practitioners actively adopt modern scientific methods in traditional medicine formulation. However, there are inexperienced and novice "inventors" who often tag their products to traditional medicinal treatments and make baseless claims, to capitalize on the anxieties of the general population during health crises. Therefore, there is a need for effective institutionalization, authorization, regulations and standardization strategies to preserve and validate traditional knowledge and ensure public health safety. This review paper aims to provide an overview on different traditional herbal medicinal approaches used worldwide to treat COVID-19 and other infectious disease outbreaks, while drawing parallel with modern medicinal practices and exploring possibilities to create synergy between the two.

\section{Discussion}

2.1. Scientific exploration of traditional herbal medicine

Medicinal plants are essential sources of new pharmaceutical targets, because of their 


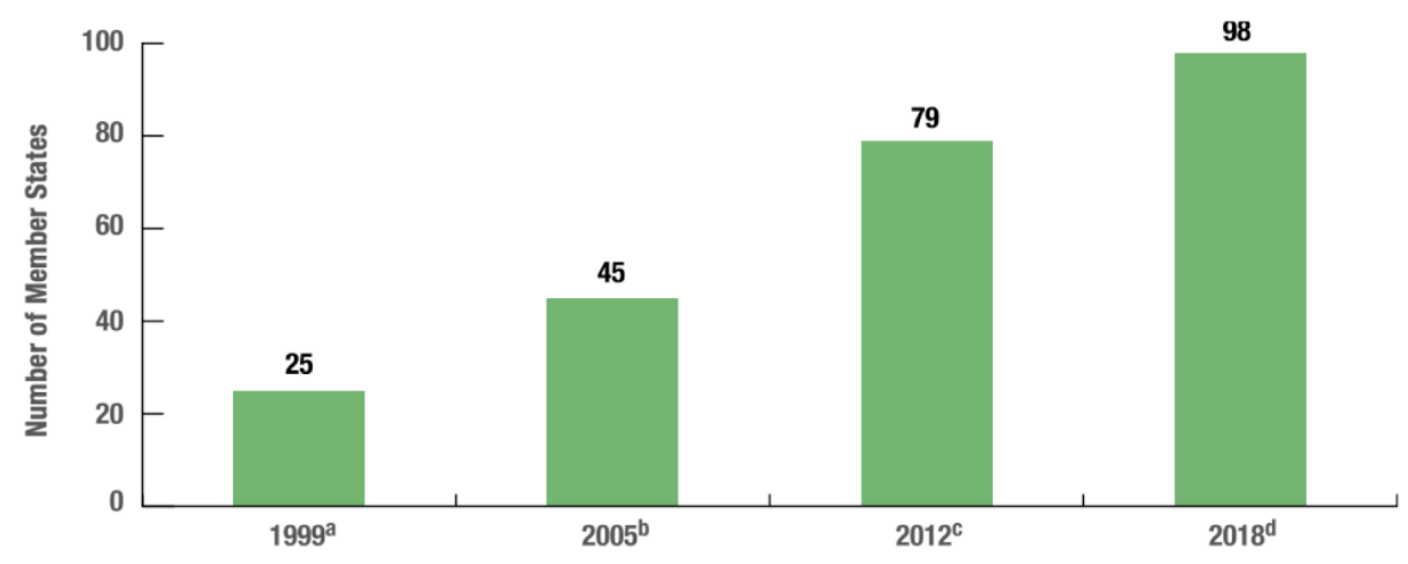

Figure 1. Growth in the number of Member States with a national policy on T\&CM, 1999-2018 (WHO, 2019).

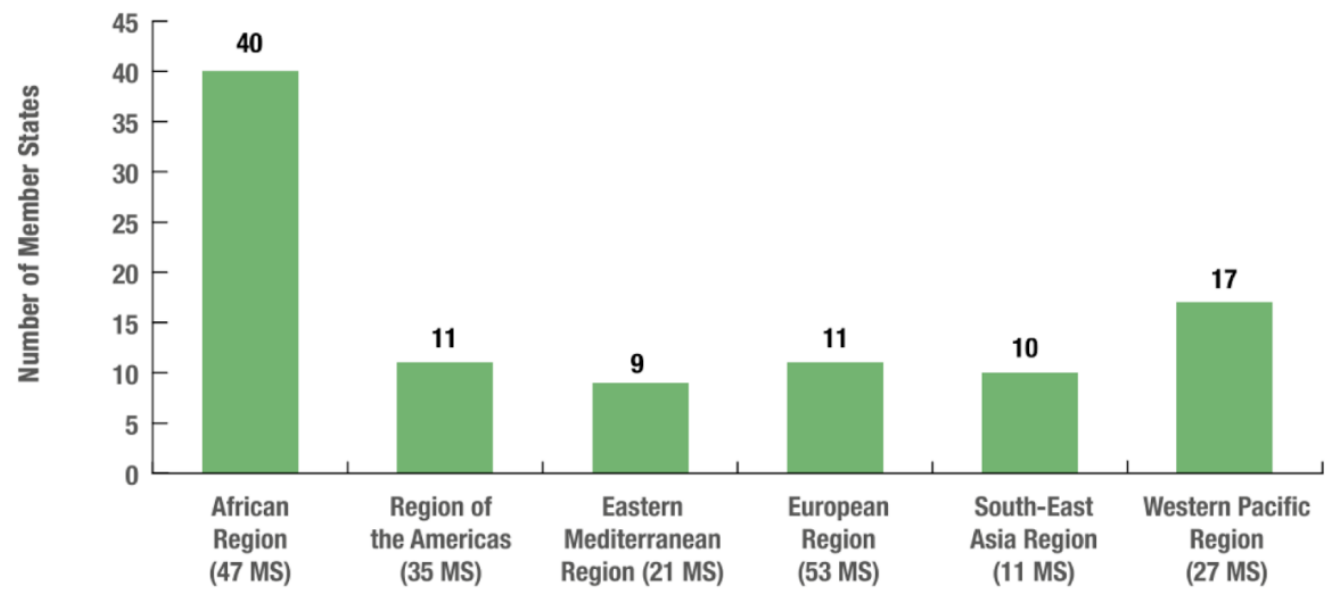

MS: Member States

Figure 2. Distribution by WHO region of Member States with national policies on T\&CM, as at 2018 (WHO, 2019).

inexhaustible array of relevant molecular entities like secondary metabolites, enzymes and scaffolds (Lung et al., 2020; Sharma and Maurya, 2020). Traditional herbal medicine has a long history of treating various infectious diseases. These medicinal herbs are effective because they contain phytochemical compounds that exhibit anti-bacterial, antiviral, immuno-modulatory, anti-cancer, and antiinflammatory properties effective against a multitude of diseases (Sen and Chakraborty, 2017; Ren et al., 2020).

\subsubsection{Drawing from the learnings and experiences of the past}

In April 2009, the highly damaging Influenza A (H1N1) was first noted in the United States and Mexico and spread rapidly to other regions of the world, resulting in the first influenza pandemic since 1968. By March 2010, the pandemic had spread to almost all the countries and killed 17,700 human beings according to the reports from the World Health Organization (WHO). WHO had recommended the use of oseltamivir (TamiFlu ${ }^{\mathrm{TM}}$ ) to manage H1N1 influenza pandemic. No direct comparative evidence to elucidate the role of oseltamivir in H1N1 influenza was reported, but some isolated cases of $\mathrm{H} 1 \mathrm{~N} 1$ virus resistance to oseltamivir were detected. Because of the high cost and shortage of oseltamivir, an urgent investigation of cheaper drug alternatives was warranted. Traditional Chinese Medicine (TCM) has been used to treat seasonal influenza for thousands of years, which has been confirmed through modern pharmacological studies. Wang et al. (2020) carried out a clinical trial using strict modern evidencebased methods (Figure 3) during H1N1 Influenza epidemic in 2009 on a total of 410 participants from 11 medical sites in 4 provinces in China using TCM formulation Maxingshigan-Yinqiaosan (MY), composed of 12 herbs. Oseltamivir and MY, as single drug formulation and in combination, reduced time to fever resolution in patients with H1N1 without any side effects suggesting MY may be an alternative treatment in alleviating fever in $\mathrm{H} 1 \mathrm{~N} 1$ influenza patients. MY treatment cost was also $70 \%$ lower compared to oseltamivir (Wang et al., 2020; Wang et al., 2011; Yang et al., 2012). 


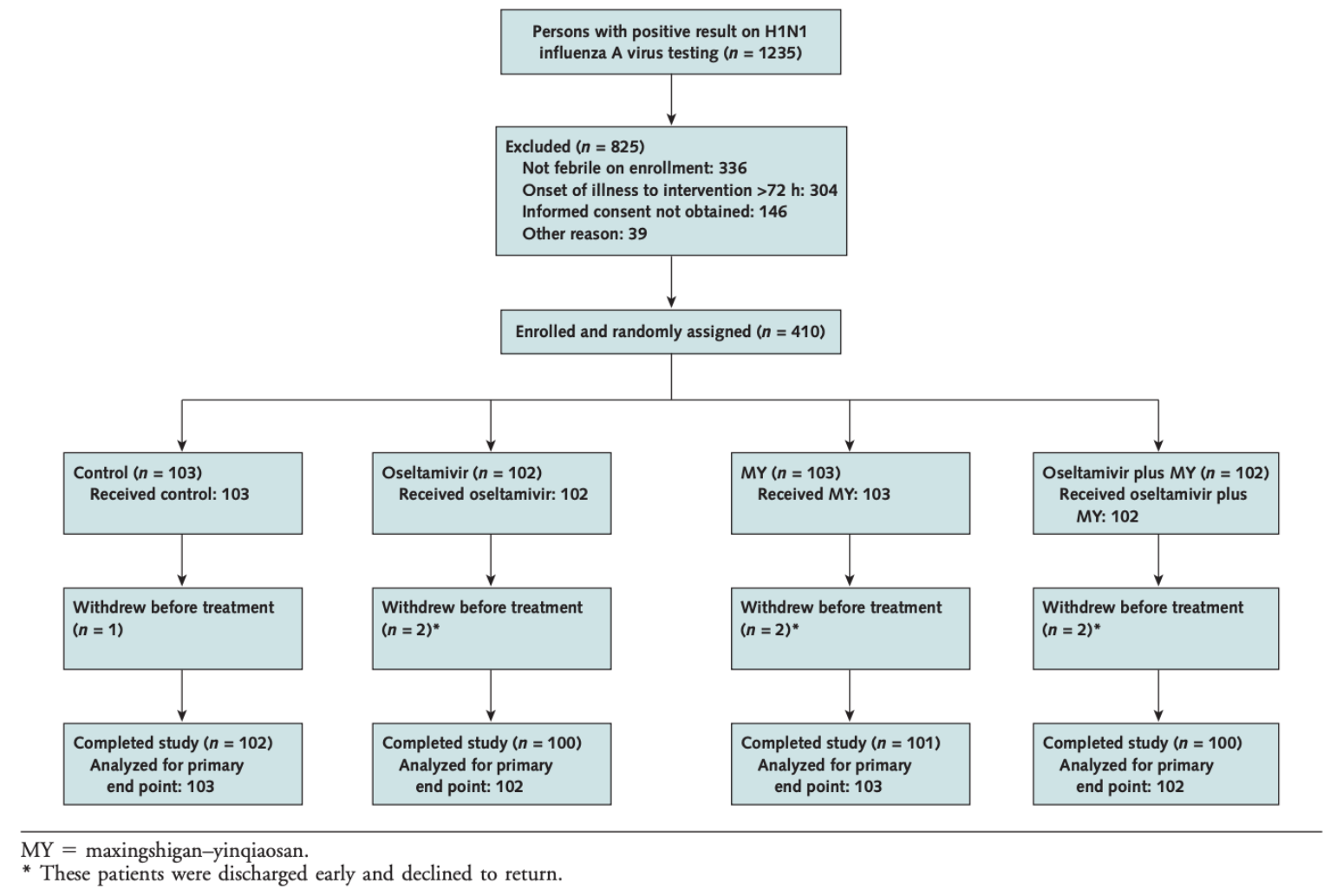

Figure 3. Study flow diagram of a clinical trial using strict modern evidence-based methods during H1N1 Influenza epidemic in 2009 (Wang et al., 2011).

Similarly, WHO recommends artemisinin-based combination therapy (ACT) for the treatment of uncomplicated malaria due to Plasmodium falciparum ACTs recommended by WHO combine an artemisinin derivative such as artemether, artesunate or dihydroartemisinin with an effective antimalarial medicine (WHO, 2010).

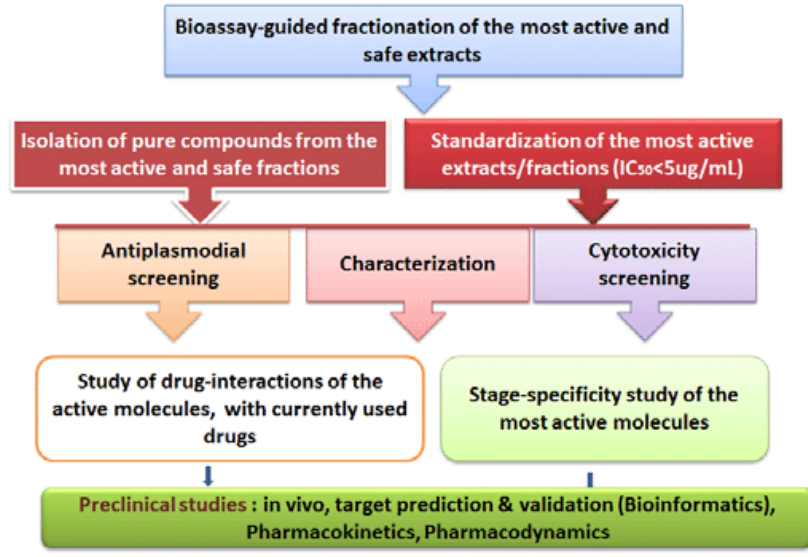

Figure 4. General protocol for malaria drug discovery and development from medicinal plants (Zofou et al., 2011).

WHO's recommendations were based on the review of scientific evidence. Traditional herbal drugs like in the case of influenza and malaria, if used as alternative or combination therapy with modern drugs, have shown huge potential to reduce the enduring challenges like drug-resistance, cost, availability, and socio-economic burden that are associated with infectious diseases. Since these challenges are concerned with almost all highly infectious diseases, there is an urgent need to broaden the repertoire of antiviral drugs, by incorporating traditional herbal medicines, to prepare better during global public health crises presented by infectious diseases.

\subsubsection{Current principles and approaches for COVID-19 treatment}

The novel coronavirus COVID-19 proposed mode of infection resembles that of SARS affecting weak, immune-compromised people as that of old people and people suffering from diabetes and chronic heart diseases. Therefore, several immuneboosting drugs are also being explored for COVID19 therapy. There are many protein domains in viruses such as spike protein and nucleocapsid protein that helps viruses to develop the capsid, replicate and attach to the host cells (Sharma and Maurya 2020; Wu et al., 2020). Known clinical treatment approaches for COVID-19 infection include drugs that act as nucleosides analogue, protease and spike protein inhibitors (Saxena, 2019). Thus, another intervention includes inhibition of viral spike protein attachment to host receptors or preventing viral replication and assembly could be strategies to cure COVID-19 infection (Wu et al., 2020). In this section, we will showcase a few examples of various therapeutic approaches. 


\subsubsection{Phytochemical and molecular investigations}

\section{a. Boosting immunity and antiviral potential}

There is a lot of evidence that viruses mainly target the body's immune system. No FDA approved drugs are available to cure the COVID-19 as of now. However, conventional medicine and therapeutic drugs are being given to patients with severe cases of viral infection, which are mainly immune-boosting drugs such as Remdesivir, originally developed to treat Hepatitis-C, but did not significantly improve the time for clinical improvement (Wang et al., 2020). In contrast to different published research on Ayurvedic and TCM it is found that the herbs used in Ayurveda and TCM are effective in inhibiting viral replication, preventing entry and attachment of virus to the host cell along with boosting the immune system of a person. Some herbs like Ashwagandha (Withania somnifera) whose immune-modulatory, antioxidant effects have been carried out in several studies over the last two decades is suggested as the effective medication in boosting immune response, and inhibiting viral replication (Tillu et al., 2020; Agarwal et al., 1999).

\section{b. Molecular docking}

The use of available sequence, homology modeling, and a number of available drugs in silico docking are being investigated to inhibit the two key target protein of COVID-19, the spike glycoprotein and 3CL protease, using modern drug compounds (Narkhede et al., 2020; Hall and Ji, 2020; Samant and Javle, 2020; Mothay and Ramesh, 2020). Similar research is being carried out by screening the potential plant-based compounds to inhibit COVID19 key proteins. In a recent research (Sharma and Maurya, 2020), various array of phytochemical and anti-viral agents present in Indian herbs like Tulsi, Haldi, Giloy, Black pepper, Ginger, Cloves, Cardamom, Lemon and Ashwagandha were analyzed to find a cure to COVID-19 infection. The phytochemical constituent and bio-active compounds present in herbs were docked with different target proteins of coronavirus such as viral capsid spike, protease to study the antiviral effect of compounds at different stages of infection. From this study it is concluded that different phytochemical compounds found in traditional medicine have strong affinity towards viral proteins that make these compounds a perfect candidate for target drug design. Likewise, in another study 83 chemical structures from TCM compounds were virtually screened using molecular docking methods, and found Theaflavin and its derivatives, obtained from black tea, can inhibit SARS-CoV 3CL (3-chymotrypsin-like cysteine) protease activity, making it a potent inhibitor compound against COVID-19 infection (Lung et al., 2020).

Similarly, Khan et al., 2020 employed computational chemistry approach for molecular docking analysis of 7 proteins of SARS-CoV-2 with 18 active constituents that have previously been reported to be antiviral or anti-SARS-CoV agents. These 18 candidate compounds were compared with 2 FDA approved drugs that have are currently being used in COVID-19, namely Remdesivir and Chloroquine (Figure 5). The results demonstrated that Epigallocatechin gallate (EGCG), a major constituent of green tea, could fit well into the binding sites of docked proteins of SARS-CoV-2 suggesting it as a lead candidate that should be further explored for the treatment of COVID-19 (Khan et al., 2020).

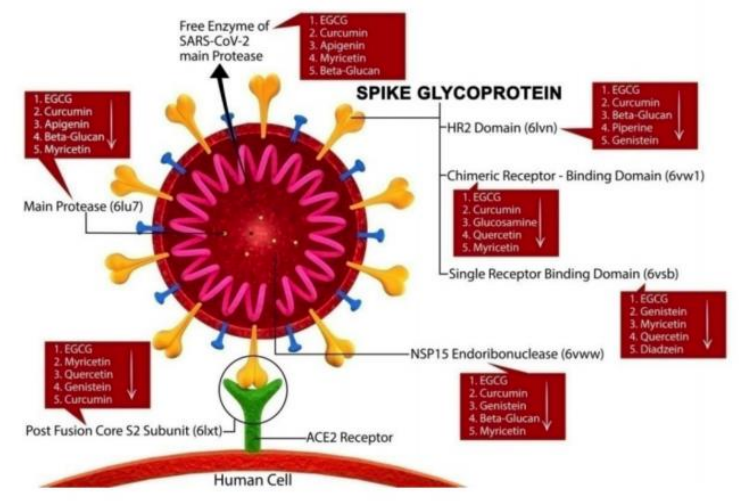

Figure 5. Diagrammatic illustrations of structural and functional proteins of SARS-CoV-2. On the basis of molecular docking, red boxes are showing suggested dietary phytochemicals, which are useful to prevent the propagation of SARS-CoV-2. In red boxes, phytochemicals are arranged in decreasing order of their activity. EGCG is the most active against all the target proteins and may have the ability to kill SARS-CoV-2 (Khan et. al., 2020).

In various case studies, case reports, randomized clinical trials, TCM treatment has been reported to cure patients suffering from SARS infection and reduce the severe side-effect of conventional medication. As COVID-19 has resemblance with SARS infection, it has been proposed that TCM can be used in treating patients suffering from COVID19. TCM researchers have also suggested the application of nasal oil to prevent SARS-COV-2 infection (Yang et al., 2020). While these initial scientific results look promising for both modern drugs and traditional herbal medicines, further studies, testings and clinical studies have to be conducted to validate the claims before a large population can take advantage of these proposed treatments. Drug discovery and clinical trials are rigorous, time-consuming and capital intensive, but synthetic drug routes seem a lot more appealing because of simpler quality control and 
standardization, ease of production, and faster relief of symptoms as compared to traditional herbal medicinal approaches. However, modern drugs also present a multitude of side effects and issues because of which the affinity towards natural products and traditional herbal medicine is slowly increasing to avoid and mitigate the harsh long term effects of using synthetic drugs. All the above mentioned articles and reviews are based on the preliminary research of different medicinal plants or formulations. Unlike conventional drugs, the purity, uniformity and potency of herbal medicine are rarely regulated. While these data are promising, extrapolated claims as if these are ready to be used in humans without clinical trials can cause public health hazards. Hence, preliminary data and research can be utilized to identify potential lead herbal medicine candidates that should be further investigated for their safety and efficacy through pharmacological studies and clinical trials before making any extrapolated claims.

\subsection{Exploration and modernization of traditional medicinal drug discovery process}

Traditional herbal medicines are very complex since they contain a multitude of bioactive molecules with multiple targets and effects. Whereas, modern single component drugs have more specific targets and effects. The complexities associated with traditional medicines present challenges in identifying efficacies and mechanisms, but also present a massive opportunity to use the same formulation for the treatment of multiple diseases. It can also shift the paradigm for drug discovery from conventional reductionism of biological and chemical research to more holistic systems approach using computational modeling methods such as virtual screening and network analysis. Some of these approaches include in silico systems biology and systems pharmacology (Fønnebø et al., 2007; Zhou et al., 2016). These methods can be utilized to elucidate the pharmacological basis of the functions of traditional medicinal plants, to identify the lead active compounds among the candidates and indicate the mechanism of action of the medicinal plants. These in silico approaches can significantly reduce lead time, cost, and in turn increase the overall efficiency of scientific exploration of traditional medicinal formulations (Figure 6).

\subsection{Challenges and opportunities in the practice of traditional herbal medicines}

In a report by WHO, they reported that four challenges to the practice of T\&CM are: lack of research data, lack of financial support for research on T\&CM, lack of mechanisms to monitor safety of
T\&CM practices, and lack of education and training for T\&CM providers (WHO, 2019).

While many countries recognize traditional medicine as an integral part of their culture and medicinal practices, proper integration of traditional medicine into the health system is still a challenge for many countries. One of the key reasons hindering the mainstreaming of traditional medicine is lack of scientific research, proper documentation of evidence and research data showing efficacy of these medicines in treating diseases. There have been efforts to increase research activities and findings in many countries, but the efforts are not sufficient to accelerate the development of traditional medicine at the pace where it can be complementary to modern medicine. Government should allocate funds to institutionalize and promote traditional medicine. For instance, according to the National Institutes of Health (NIH) in the United States, they allocated 366 million USD categorical funding in FY 2016 under "Complementary and Alternative Medicine" (WHO, 2019).

Mechanism for safety and quality control of herbal medicines should also be adopted to control or govern manufacturers and producers of herbal medicines. For example, a regulation would state that herbal medicines must have been proven to be safe, effective and of good quality before reaching the public (WHO, 2019). Many case reports suggest , which clinical toxicity related to the use of Ayurvedic medicine and most of the toxins are heavy metals like lead and mercury. In 2008, India came up with the National Pharmacovigilance Programme for Ayurveda to regulate the use of ancient medicinal practices (Patwardhan et al., 2017). However, many countries lack this mechanism.

Additionally, an institutionalization mechanism to conserve the traditional knowledge is of utmost importance. Many countries have government funded initiatives and research centers to promote traditional medicine. Some examples are - Ayurveda Community Health Promotion Service in Srilanka (ACHPS), four national institutes (Central Council for Research in Ayurveda and Siddha, the Central Council for Research in Unani Medicine, the Central Council for Research in Yoga and Naturopathy, and the Central Council for Research in Homeopathy) that undertake research for $\mathrm{T} \& \mathrm{CM}$ in India, Ayurveda Research and Training Center and SowaRigpa Medical School in Nepal, etc. However, research and development on dosage, processing, techniques are still quite lacking in the herbal sector compared to allopathic medicine.

Intellectual property rights (IPR) promotion and protection should be a priority to commercialize traditional herbal formulations and prevent 

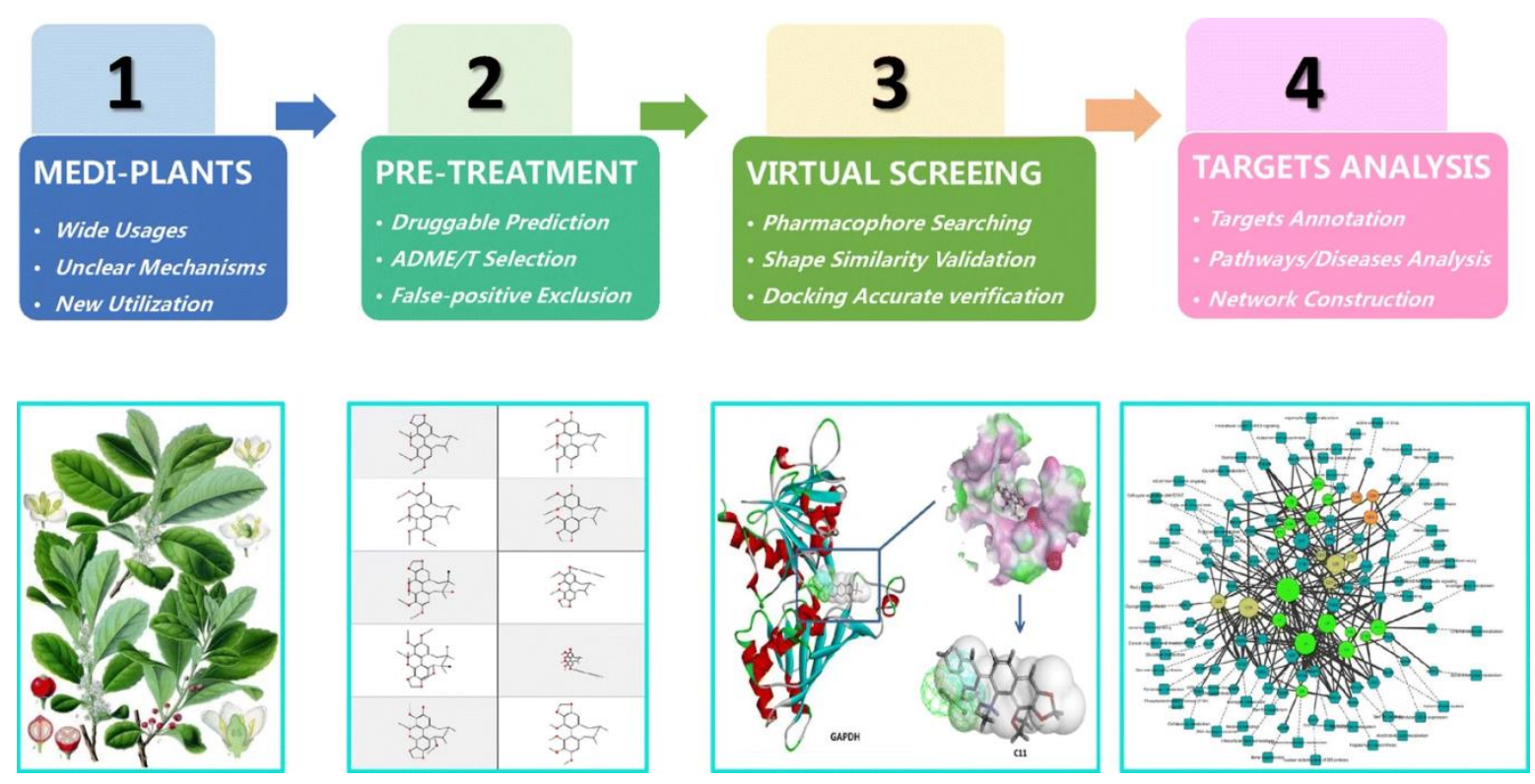

Figure 6. The overall design of in silico methodology to predict the pharmacological attributes of traditional medicinal plants. (Yi et al., 2018)

biopiracy. Proper documentation and traditional knowledge databases therefore become keys to making sure the traditional knowledge is well protected through IPR. As shown in Figure 1, 98 member states of WHO already have included traditional medicine in their national policy, it is equally important to make sure it is also an integral part of national IPR policy document. Nepal took a progressive step in 2019 and has incorporated promotion and conservation of traditional knowledge as a separate title in both National Science and Technology Policy, 2019 and National Intellectual Property Protection Policy, 2019 to highlight the importance of traditional knowledge and the need for reform in this sector.

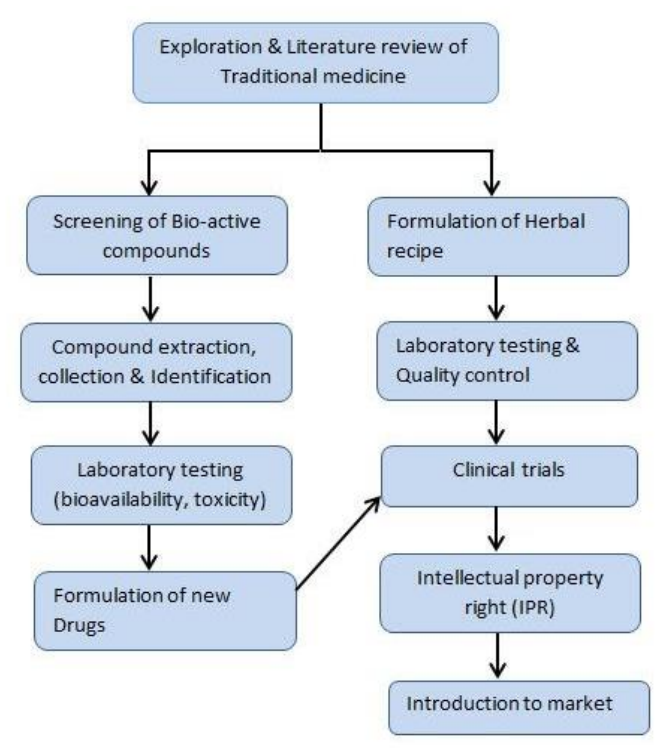

Figure 7. Exploration from traditional herbal medicine using scientific methods
These policy documents are the foundation upon which countries need to step to build strong implementation strategies and work plans with the support from experts in related areas.

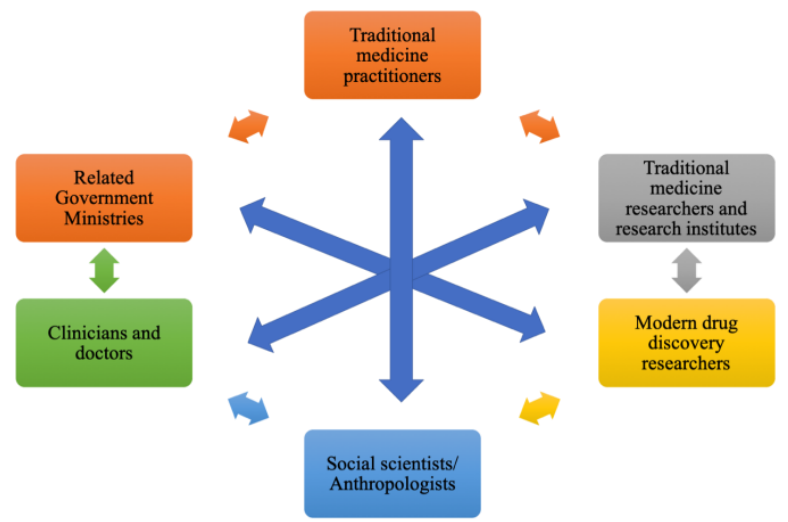

Figure 8. Collaboration and partnership networks in drug discovery research with traditional medicine incorporated in it

\section{Conclusions}

This review paper has highlighted the current scientific research efforts on both traditional and allopathic medicine realms to find a treatment for COVID-19. While doing so, we have drawn parallels between traditional and modern medicinal approaches, showed how they are interconnected (e.g., many modern drugs are bio-derived/inspired), and finally proposed ways to revive and modernize traditional medicine. We have also warranted actions to strengthen the traditional medicine ecosystem to ensure the safety and quality of these medicines, on par with stringent regulations for modern medicines. There is plenty of evidence to justify the need for a multipronged approach by combining scientific and traditional knowledge to drive success in disease management. 
Many countries have been able to integrate traditional medicine into their health systems and use traditional medicines in combination or as alternatives to allopathic medicines even to manage infectious diseases that are pandemic and endemic in nature. In fact, use of traditional medicine is proven to be a successful strategy to prevent drug-resistance in various infectious diseases. Traditional medicine, a time tested medicinal therapy since ages, has a great potential to enable an improved health care system, but there has to be a proper mechanism to address its limitations as well. Finally, innovation and knowledge cannot thrive in a silo. Partnerships and collaborations among stakeholders from government, private, academia and public sectors are vital to bring all these different important elements together for modernization and mainstreaming of traditional knowledge (Figure 8). Evidence-based incorporation of traditional medicine into drug discovery and clinical practice will help provide quality healthcare to all. It is good to be optimistic, but mainstreaming traditional medicine is a long road for many countries including Nepal where traditional medicinal practices are in amorphous forms. But, it is possible to accelerate change with a strategic roadmap and initiatives from the government for revival and modernization of traditional herbal medicine as an integral part of the healthcare system. COVID-19 pandemic and other pandemics that render human beings helpless are reminders that we need to be prepared for such crises and a holistic approach of combining traditional and modern medicine could be one of the ways to better cope with such health crises.

Acknowledgments: This work was carried out with the aid of a grant from UNESCO and the International Development Research Center, Ottawa, Canada. The views expressed herein do not necessarily represent those of UNESCO, IDRC or its Board of Governors.

Author Contributions: A.B. and A.M. have contributed equally to the review article and their names were written in alphabetically.

Conflicts of Interest: The authors declare no conflict of interest.

\section{References}

Agarwal R, Diwanay S, Patki P, Patwardhan B. Studies on immunomodulatory activity of Withania somnifera (Ashwagandha) extracts in experimental immune inflammation. Journal of Ethnopharmacology. 1999 Oct 1;67(1):27-35. https://doi:10.1016/s0378-8741(99)00065-3

Ang L, Lee HW, Choi JY, Zhang J, Lee MS. Herbal medicine and pattern identification for treating COVID19: a rapid review of guidelines. Integrative Medicine Research. $2020 \quad$ Mar 29:100407. https://doi.org/10.1016/j.imr.2020.100407

Ben-Shabat S, Yarmolinsky L, Porat D, Dahan A. Antiviral effect of phytochemicals from medicinal plants:
Applications and drug delivery strategies. Drug Delivery and Translational Research. 2020 Dec 10(2): 354-367. https://doi.org/10.1007/s13346-019-00691-6

Fønnebø V, Grimsgaard S, Walach H, Ritenbaugh C, Norheim AJ, MacPherson H, Lewith G, Launs $\varnothing$ L, Koithan M, Falkenberg T, Boon H. Researching complementary and alternative treatments-the gatekeepers are not at home. BMC medical research methodology. $2007 \quad$ Dec;7(1):7, 1 6.https://doi.org/10.1186/1471-2288-7-7

Hall Jr DC, Ji HF. A search for medications to treat COVID19 via in silico molecular docking models of the SARSCoV-2 spike glycoprotein and 3CL protease. Travel medicine and infectious disease. 2020 Apr 12:101646. https://doi.org/https://doi.org/10.1016/j.tmaid.2020.101646

Khan MF, Khan MA, Khan ZA, Ahamad T, Ansari WA. Identification of Dietary Molecules as Therapeutic Agents to Combat COVID-19 Using Molecular Docking Studies. Research Square, 2020 Mar 1-17. https://doi.org/10.21203/rs.3.rs-19560/v1

Lin LT, Hsu WC, Lin CC. Antiviral natural products and herbal medicines. Journal of traditional and complementary medicine. 2014 Jan 1;4(1):24-35. https://doi.org/10.4103/2225-4110.124335

Lung J, Lin YS, Yang YH, Chou YL, Shu LH, Cheng YC, Liu HT, Wu CY. The potential chemical structure of antiSARS-CoV-2 RNA-dependent RNA polymerase. Journal of Medical Virology. 2020 Jun;92(6):693-697. https://doi.org/10.1002/jmv.25761

Maurya DK, Sharma D. Evaluation of traditional ayurvedic preparation for prevention and management of the novel Coronavirus (SARS-CoV-2) using molecular docking approach.

https://doi.org/10.26434/chemrxiv.12110214.v1

Maurya V.K., Kumar S., Bhatt M.L.B., Saxena S.K. (2020) Therapeutic Development and Drugs for the Treatment of COVID-19. In: Saxena SK. (ed.) Coronavirus Disease 2019 (COVID-19). Medical Virology: From Pathogenesis to Disease Control. Springer, Singapore. https://doi.org/10.1007/978-981-15-4814-7_10

Mothay D, Ramesh KV. Binding site analysis of potential protease inhibitors of COVID-19 using AutoDock. VirusDisease. $2020 \quad$ May $2: 1$. https://doi.org/10.1007/s13337-020-00585-Z

Narkhede R, Cheke RS, Ambhore J, Shinde S. The Molecular Docking Study of Potential Drug Candidates Showing Anti-COVID-19 Activity by Exploring of Therapeutic Targets of SARS-CoV-2. Eurasian Journal of Medicine and Oncology, 4(3), 185-195. https://doi.org/10.14744/ejmo.2020.31503

Patwardhan K, Pathak J, Acharya R. Ayurveda formulations: A roadmap to address the safety concerns. Journal of Ayurveda and integrative medicine. 2017 Oct 1;8(4):279282. https://doi.org/10.1016/j.jaim.2017.08.010

Rastogi S, Pandey DN, Singh RH. COVID-19 Pandemic: A pragmatic plan for Ayurveda Intervention. Journal of Ayurveda and Integrative medicine. 2020 Apr 23. https://doi.org/10.1016/j.jaim.2020.04.002

Rates SM. Plants as source of drugs. Toxicon. 2001 May 1;39(5):603-13. 0101(00)00154-9

https://doi.org/10.1016/S0041-

Ren JL, Zhang AH, Wang XJ. Traditional Chinese medicine for COVID-19 treatment. Pharmacological research. 2020 May;155:104743.

https://doi.org/10.1016/j.phrs.2020.104743 
Robertson E. Medicinal plants at risk. Nature's pharmacy, our treasure chest: why we must conserve our natural heritage. Center for Biological Diversity, Tucson, AZ. 2008.

Samant L, Javle V. Comparative Docking analysis of rational drugs against COVID-19 Main Protease. ChemRxiv, April 2020. https://doi.org/10.26434/chemrxiv.12136002.v1 https://europepmc.org/article/ppr/ppr152658

Saxena SK. Current Insight into the Novel Coronavirus Disease 2019 (COVID-19). In: Saxena SK (ed.), Coronavirus Disease 2019 (COVID-19), Medical Virology: From Pathogenesis to Disease Control. Springer, Singapore 10.1007/978-981-15-4814-7.

Sen S, Chakraborty R. Revival, modernization and integration of Indian traditional herbal medicine in clinical practice: Importance, challenges and future. Journal of traditional and complementary medicine. 2017 Apr https://doi.org/10.1016/j.jtcme.2016.05.006

$1 ; 7(2): 234-244$

Sen S, Chakraborty R. Revival, modernization and integration of Indian traditional herbal medicine in clinical practice: Importance, challenges and future. Journal of traditional and complementary medicine. 2017 Apr 1;7(2):234-44.

Tillu G, Chaturvedi S, Chopra A, Patwardhan B. Public health approach of Ayurveda and Yoga for COVID-19 prophylaxis. The Journal of Alternative and Complementary Medicine. 2020 May 1;26(5):360-364. https://doi.org/10.1089/acm.2020.0129

ul Qamar MT, Alqahtani SM, Alamri MA, Chen LL. Structural basis of SARS-CoV-2 3CLpro and antiCOVID-19 drug discovery from medicinal plants. Journal of pharmaceutical analysis. 2020 Mar 26. https://doi.org/10.1016/j.jpha.2020.03.009

Wang C., Cao B., Liu Q.-Q., Zou Z.-Q., Liang Z.-A, Gu L., Dong J.-P., Liang L.-R., Li X.-W., Hu K., He X.-S. Oseltamivir compared with the Chinese traditional therapy Maxingshigan-Yinqiaosan in the treatment of H1N1 influenza: a randomized trial. Annals of internal medicine. 2011 Aug 16;155(4):217-25.. https://doi.org/10.7326/0003-4819-155-4-20110816000005

Wang Y, Zhang D, Du G, Du R, Zhao J, Jin Y, Fu S, Gao L, Cheng Z, Lu Q, Hu Y. Remdesivir in adults with severe COVID-19: a randomised, double-blind, placebocontrolled, multicentre trial. The Lancet. 2020 Apr 29. https://doi.org/10.1016/S0140-6736(20)31022-9
World Health Organization [WHO]. Guidelines for the treatment of malaria. 2010 [cited 2020 May 19]. Available from: https://www.who.int/docs/defaultsource/documents/publications/gmp/guidelines-for-thetreatment-of-malaria-eng.pdf?sfvrsn=a0138b77_2

World Health Organization [WHO]. WHO global report on traditional and complementary medicine. 2019 [cited 2020 May]. Available from: https://apps.who.int/iris/bitstream/handle/10665/312342/ 9789241515436-eng.pdf?ua $=1$

Worldometer. COVID-19 Coronavirus Pandemic. 2020. [May 20]. Available from: https://www.worldometers.info/coronavirus/

Wu C, Liu Y, Yang Y, Zhang P, Zhong W, Wang Y, Wang Q, Xu Y, Li M, Li X, Zheng M. Analysis of therapeutic targets for SARS-CoV-2 and discovery of potential drugs by computational methods. Acta Pharmaceutica Sinica B. 2020 Feb 27. https://doi.org/10.1016/j.apsb.2020.02.008

Yang SG, Cao B, Liang LR, Li XL, Xiao YH, Cao ZX, Jia HY, Yu HJ, Xu Z, Gu L, Yang YD. Antiviral therapy and outcomes of patients with pneumonia caused by influenza A pandemic (H1N1) virus. PloS ONE. 2012;7(1). https://doi.org/10.1371/journal.pone.0029652

Yang Y, Islam MS, Wang J, Li Y, Chen X. Traditional Chinese medicine in the treatment of patients infected with 2019-new coronavirus (SARS-CoV-2): a review and perspective. International journal of biological sciences. 2020;16(10):1708-1717. https://doi.org/10.7150/ijbs.45538

Yi F, Li L, Xu LJ, Meng H, Dong YM, Liu HB, Xiao PG. In silico approach in reveal traditional medicine plants pharmacological material basis. Chinese medicine. 2018 Dec;13(1):33. https://doi.org/10.1186/s13020-018-0190-0

Zhang D, Zhang B, Lv JT, Sa RN, Zhang XM, Lin ZJ. The clinical benefits of Chinese patent medicines against COVID-19 based on current evidence. Pharmacological Research. $\quad 2020 \quad$ May 5:104882. https://doi.org/10.1016/j.phrs.2020.104882

Zhou W, Wang J, Wu Z, Huang C, Lu A, Wang Y. Systems pharmacology exploration of botanic drug pairs reveals the mechanism for treating different diseases. Scientific reports. 2016 Nov 14;6(1):1-7. https://doi.org/10.1038/srep36985

Zofou D, Kowa TK, Wabo HK, Ngemenya MN, Tane P, Titanji VP. Hypericum lanceolatum (Hypericaceae) as a potential source of new anti-malarial agents: a bioassayguided fractionation of the stem bark. Malaria Journal. 2011 Dec;10(1):167. https://doi.org/10.1186/1475-2875-10-167 